\title{
A profissionalização da gestão do voluntariado: um estudo de caso do departamento de voluntários do Hospital Israelita Albert Einstein
}

The professionalization of volunteer management: a case study of the Volunteers Department of the Hospital Israelita

\section{Albert Einstein}

\author{
Sheila Patrícia Ramos Beckhauser \\ Universidade Regional de Blumenau, Programa de Pós-Graduação \\ em Administração, Blumenau, SC, Brasil. \\ E-mail: spr8oscœgmail.com \\ Maria José Carvalho de Souza Domingues \\ Universidade Regional de Blumenau, Programa de Pós-Graduação \\ em Administração, Blumenau, SC, Brasil. \\ E-mail: mjcsd2008ळgmail.com
}

\section{Resumo}

O trabalho voluntário passa de uma ação assistencialista para um processo que requer inovações de modo a alcançar eficiência em seus resultados, levando à profissionalização da gestão e obedecendo a critérios organizativos e estratégicos. Este estudo tem como objetivo compreender como é realizada a gestão do voluntariado a partir de um estudo de no Departamento de Voluntários do Hospital Israelita Albert Einstein. A pesquisa caracteriza-se como exploratória e qualitativa. Para coleta dos dados, foram utilizados documentos, observação e entrevistas. Foram entrevistados um coordenador e seis voluntários. Para análise dos dados, utilizou-se a análise de conteúdo e a técnica categorial. Os resultados apontam que o voluntariado não pode agir de maneira independente dentro do hospital, embora a autonomia seja necessária para poder implementar ações que tragam resultados. $\mathrm{O}$ voluntariado deve atuar de maneira a se adequar às regras do hospital. Todas as suas ações precisam estar de acordo com os princípios e objetivos da instituição. Acredita-se que a gestão do voluntariado vai muito além da gestão de pessoas, gestão participativa, resultados ou aspectos assistencialistas, envolvendo aspectos mais amplos e processos tradicionais de administração juntamente com as características do voluntariado. A profissionalização da gestão é fundamental para buscar o aperfeiçoamento, a inovação e instrumentos que permitam prestar contas e ainda administrar todas as dinâmicas que envolvem o voluntariado.

Palavras-chave: Hospital; Voluntariado; Gestão do Voluntariado. 
Voluntary work turns from a welfare action into a process that requires innovations in order to have efficient results, which leads to professional management, and follows organizational and strategic criteria. This study aims to understand how volunteer management is carried out by a case study performed in the Volunteer Department of Hospital Israelita Albert Einstein. This is an exploratory and qualitative research. Interviews, observations and documents were used on data collection. We interviewed one coordinator and six volunteers. We used data analysis and the categorical technique to analyze information. Results indicate that volunteering cannot be independent within the hospital, although autonomy is necessary to implement actions that bring results to the hospital. Volunteers should act in a manner that conforms to hospital rules, thus, all of their actions need to concur with the hospital's principles and goals. Volunteering management is more than people management, participatory management, results or assistance aspects; it involves broader elements and traditional management processes along with volunteering characteristics. Volunteering management professionalization is essential to improvement, innovation and instruments search, hence it can be accountable and still manage all volunteering dynamics.

Keywords: Hospital; Volunteering; Volunteer management.
O voluntariado no Brasil pode ser constatado já entre os primeiros grupos de portugueses, na construção da primeira Santa Casa, um hospital inaugurado por volta do ano de 1543 (Sobolh; Widman, 2011). No entanto, uma forma mais organizada de voluntariado se deu nos anos 1990, com a criação de centros responsáveis pela divulgação, capacitação e organização dos voluntários no país (Dohme, 2001).

Para Dohme (2001), cabe à organização definir, gerir e garantir que a força do trabalho voluntário será eficientemente utilizada, contribuindo para o desenvolvimento do projeto social ao qual está alocado. Corullón e Medeiros Filho (2002) afirmam que para a organização é fundamental criar e manter um programa de voluntariado em sintonia com seus valores e objetivos, passando a ter uma função até mesmo estratégica. Dessa forma, cabe à organização não apenas apoiar as ações voluntárias, mas gerenciá-las com critérios de eficiência, criando um programa específico alocado a algum departamento e contando com a presença de um coordenador que irá acompanhar e avaliar o trabalho voluntário.

O hospital, conforme Foucault (1984), tem em suas origens (antes do século XVIII) uma função essencialmente assistencial, sendo um local onde atuavam pessoas com espírito caritativo (religioso ou leigo). Ao longo do tempo esta situação foi mudando, e o hospital deixou de ser um lugar de assistência aos pobres para se tornar uma instituição com mecanismos disciplinares aliados ao saber e à prática médica. Toda essa transformação não impediu que ainda se encontre no hospital pessoas com espírito caritativo, hoje representadas pelo voluntariado.

No que tange ao gerenciamento do voluntariado em hospitais, destacam-se os estudos de Okabayashi e Costa (2008), Porciuncula (2009), Silva e Moretto Neto (2012) e Rodrigues, Meyer Junior e Cruz (2014). Esses estudos identificaram a falta de profissionalização da gestão do trabalho voluntário e presença de aspectos assistencialistas e descompromissados, assim como relatos de escassez de recursos e necessidade de melhor qualificação. Entretanto, constataram-se também aspectos positivos da presença do voluntariado nos hospitais, como melhoria da gestão do 
próprio hospital, melhorando sua imagem social e legitimidade institucional. Foram identificados aspectos de gestão social, gestão participativa realizada por meio de um processo democrático e gestão estratégica de pessoas alinhadas aos objetivos da organização. $\mathrm{O}$ assistente social foi tido como referência profissional no voluntariado no hospital.

Meyer Junior, Pascucci e Murphy (2012) afirmam que, no caso dos hospitais, os voluntários podem ter uma contribuição decisiva para a estratégia, onde microações podem desempenhar papéis significativos para a realização de seu objetivo e para o desempenho do hospital. Os voluntários podem ajudar a reduzir o custo operacional, captar recursos, melhorar a imagem do hospital e contribuir para o serviço de atendimento psicossocial à pacientes, familiares e colaboradores.

O objeto desta pesquisa é o Departamento de Voluntários do Hospital Israelita Albert Einstein, localizado em São Paulo (SP). O hospital foi o primeiro na América Latina cuja gestão do voluntariado conquistou a Certificação ISO 9oo1. Essa conquista foi resultado da implantação de um sistema de qualidade que contribuiu para a profissionalização do Departamento de Voluntários.

Assim, considerando a relevância do trabalho de gestão do voluntariado em hospitais, caracterizados como organizações complexas, este estudo procura responder a seguinte pergunta de pesquisa: "Como é realizada a gestão do voluntariado no Hospital Israelita Albert Einstein?”. Tem-se como pressuposto que o trabalho voluntário é conduzido sob alguma forma de gestão, obedecendo a critérios organizativos, como processos e normas que conduzem sua atuação, buscando atender os objetivos estratégicos da organização.

Este trabalho busca contribuir com os estudos relacionados ao tema e, ainda, fornecer informações para hospitais e instituições que pretendem incorporar ou que já possuem voluntariado, buscando aprimorar sua gestão.

\section{Gestão do voluntariado}

O voluntário se beneficia de sua ação, seja de maneira espiritual, afetiva, política ou ideológica.
E a organização que apoia e recebe essa força de trabalho também se beneficia, melhorando sua coesão social, diretamente ligada à questão da responsabilidade social (Corullón; Medeiros Filho, 2002; Dohme, 2001; Engel, 2012). No entanto, como destaca Dohme (2001), o trabalho voluntário, embora seja uma ação espontânea e gratuita, não dispensa regras, planejamento e organização.

A gestão do voluntariado implica em possuir um programa que balizará um sistema de regras, de supervisão e de motivação capaz de aproveitar de forma otimizada o potencial de trabalho (Dohme, 2001). Assim, um programa de voluntários deve conter as providências descritas no Quadro 1.

Domeneghetti (2001) afirma que, de maneira geral, a missão do voluntariado é dar sustento e apoio às iniciativas e projetos da entidade, operacionalizar as ações em conjunto com a organização e atender a clientela de todas as formas necessárias. Em relação à contribuição estratégica do voluntariado, Corullón e Medeiros Filho (2002, p. 65) afirmam que

um programa de voluntariado em sintonia com os valores, missão e objetivos de negócio da empresa passa a ter uma função estratégica. Reforça a cultura interna, amplia o alcance para a sociedade de suas operações e colabora para a inserção da empresa em vários segmentos de público de seu interesse.

Teodósio (2001) afirma que um grupo mínimo de pessoas remuneradas é necessário. Quanto mais especializado for o serviço oferecido pela organização, maior a necessidade de adotar procedimentos de treinamento estruturados.

Corullón e Medeiros Filho (2002) afirmam que as principais responsabilidades de gerenciamento são tarefas do coordenador. Em uma empresa pequena, ele será suficiente para coordenar, já em uma grande empresa, será necessário o apoio de uma equipe. Fica sob sua responsabilidade o planejamento, a comunicação interna, a seleção e o encaminhamento de voluntários e de projetos a apoiar ou desenvolver, a orientação e formação para a ação, o monitoramento, a avaliação e a divulgação dos resultados. O programa precisa ser um espaço democrático, aberto ao debate, à crítica e à livre circulação de ideias, sem 
prescindir da disciplina que implica na supervisão, monitoramento e avaliação que cabem ao coordenador do gerenciamento do voluntariado. O Quadro 2 apresenta o detalhamento de algumas das funções do coordenador.

O coordenador pode ser um profissional remunerado e, dependendo do tamanho da organização e do corpo de voluntários, poderá ter maiores ou menores atribuições, entre as quais se destacam: articular o envolvimento do voluntário na organização, desenvolver programas e objetivos, estabelecer as funções voluntárias, coordenar o planejamento de turnos, determinar políticas e procedimentos, gerenciar orçamento, desenvolver novos projetos, entre outras atividades (Dohme, 2001).

\section{Quadro I - Processos do gerenciamento do voluntariado}

\begin{tabular}{|c|c|c|}
\hline Atividade & Tarefa & Descrição \\
\hline \multirow{5}{*}{ Recrutamento } & Captação & $\begin{array}{l}\text { A organização necessita divulgar constantemente seu trabalho para captar novos } \\
\text { voluntários, seja para novos projetos ou para garantir o número mínimo de voluntários } \\
\text { atuantes. }\end{array}$ \\
\hline & Seleção & $\begin{array}{l}\text { A organização deve possuir um sistema próprio de seleção e estar sempre preparada para } \\
\text { colocá-lo em prática. o processo de seleção envolve entrevista, expondo ao candidato } \\
\text { os elementos necessários para sua atuação, e a avaliação prévia de sua adequação } \\
\text { às necessidades da vaga, considerando habilidade, intenção, disponibilidade, } \\
\text { sensibilidade, entusiasmo, atitudes etc. }\end{array}$ \\
\hline & Contrato & $\begin{array}{l}\text { Após a seleção, o candidato deverá assinar o Termo de Adesão, em que consta tipo de } \\
\text { trabalho a ser realizado, frequência e horário, entre outros, o que eximirá a organização } \\
\text { social de possiveis implicações de ordem trabalhista. }\end{array}$ \\
\hline & Integração & $\begin{array}{l}\text { o voluntário deve ser informado da estrutura da organização (organograma, estatutos, } \\
\text { missão, objetivos, regimento interno, regras cotidianas, política do voluntariado etc.). }\end{array}$ \\
\hline & Orientação & $\begin{array}{l}\text { Envolve treinamento, informação e conhecimento. Pode-se aplicar cursos, jogos, } \\
\text { dinâmicas de grupo, estudos de caso etc. }\end{array}$ \\
\hline \multirow{3}{*}{ Execução } & $\begin{array}{l}\text { Estrutura de } \\
\text { equipes }\end{array}$ & $\begin{array}{l}\text { O trabalho voluntário se desenvolve geralmente em equipes. Além disso, muitos objetivos } \\
\text { só podem ser atingidos em grupo. Neste sentido, deve-se considerar delimitar as funções } \\
\text { de cada equipe, definir sua composição e escolher seus líderes. }\end{array}$ \\
\hline & Capacitação & $\begin{array}{l}\text { Envolve programas de capacitação de conteúdos, como reciclagem, área social de } \\
\text { atuação, função ou rotina específica que será desempenhada, entre outros. }\end{array}$ \\
\hline & Avaliação & $\begin{array}{l}\text { Avaliação de desempenho e estabelecimento de metas que devem ser realizados por } \\
\text { todas as pessoas envolvidas no processo. }\end{array}$ \\
\hline \multirow{2}{*}{ Término } & $\begin{array}{l}\text { Remanejamento } \\
\text { de carreira }\end{array}$ & $\begin{array}{l}\text { Pode-se gerenciar o término do trabalho voluntário por meio de contrato com prazo } \\
\text { determinado. Ao final, perante avaliação e desejo das partes, pode-se renovar o } \\
\text { contrato, assim como remanejar o voluntário para outras funções. }\end{array}$ \\
\hline & Reconhecimento & $\begin{array}{l}\text { O reconhecimento pode ser realizado de diversas maneiras, como entrega de algum } \\
\text { símbolo ou lembrança, eventos criados para esse fim ou agradecimentos sistemáticos } \\
\text { (elogios e cumprimentos no dia a dia). }\end{array}$ \\
\hline
\end{tabular}


Os estudos internacionais sobre voluntariado evidenciam a necessidade de profissionalização. A falta de uma gestão eficaz compromete os resultados e impacta na retenção do voluntário. Conforme afirmam Hwang e Powell (2009), o crescimento da profissionalização da gestão representa uma mudança institucional profunda. A gerência profissional vincula a organização e seus ambientes, facilita o fluxo de informações, apresenta novos domínios de trabalho e ergue novas hierarquias de status baseadas no prestígio da formação e do emprego. Nos Estados Unidos, por exemplo, organizações sem fins lucrativos contam com profissionais contratados para atuar na gestão para alcançar metas e também sua missão.

\section{Quadro 2 - Funções do coordenador do voluntariado}

\begin{tabular}{|l|l|}
\hline \multicolumn{1}{|l}{$\begin{array}{l}\text { Atividade } \\
\begin{array}{|l}\text { Supervisão e } \\
\text { monitoramento }\end{array}\end{array}$} & $\begin{array}{l}\text { Descrição } \\
\text { atividade para verificar se está sendo realizada adequadamente e se as necessidades dos voluntários estão } \\
\text { sendo satisfeitas. }\end{array}$ \\
\hline $\begin{array}{l}\text { Avaliação do } \\
\text { desempenho } \\
\text { pessoal e de } \\
\text { resultados }\end{array}$ & $\begin{array}{l}\text { Inclui construção compartilhada de métodos de avaliação e reuniões de autoavaliação que permitem críticas } \\
\text { construtivas e servem para transmitir experiências, revisar modos de agir e antecipar necessidades. Podem ser } \\
\text { avétodos, presença e participação nas sessões de capacitação, realização das tarefas, entre outros. A avaliação } \\
\text { dos resultados permite ter clareza dos progressos alcançados, bem como identificar problemas e corrigi-los. } \\
\text { Pode-se fazer uso de indicadores e números para medir e apresentar os resultados alcançados. }\end{array}$ \\
\hline $\begin{array}{l}\text { Planejamento } \\
\text { Os programas de voluntariado precisam ser planejados e periodicamente replanejados. Uma das funções da } \\
\text { avaliação é fornecer dados para o replanejamento, incluindo o que vai mal, mas também a descoberta de } \\
\text { novas demandas. }\end{array}$ \\
\hline
\end{tabular}

Fonte: adaptado de Corullón e Medeiros Filho, 2002

\section{Procedimentos metodológicos}

A metodologia foi conduzida sob abordagem qualitativa, utilizando a estratégia de estudo de caso, tendo como objeto o Departamento de Voluntários do Hospital Israelita Albert Einstein, onde foram investigadas as práticas de gestão desenvolvidas.

Richardson (2012) afirma que a abordagem qualitativa de um problema justifica-se sobretudo por ser uma forma adequada para entender a natureza de um fenômeno social que diz respeito a aspectos da realidade que não podem ser quantificados. Já a condução da pesquisa sob a estratégia de estudo de caso, refere-se à investigação de um fenômeno em profundidade, em um contexto específico (Yin, 2005).
A pesquisa caracteriza-se também como exploratória por existirem poucos estudos científicos abordando o tema da gestão do voluntariado em hospitais (Okabayashi e Costa, 2008; Porciuncula, 2009; Rodrigues, 2014; Silva e Moretto Neto, 2012). Richardson (2012) afirma que o estudo é exploratório quando se tem pouco conhecimento prévio sobre o problema.

Os sujeitos da pesquisa foram a coordenadora responsável pelo voluntariado e os próprios voluntários. O Quadro 3 apresenta o perfil dos entrevistados da pesquisa. As técnicas de coleta de dados empregadas foram: entrevistas semiestruturadas, documentos e observação. As entrevistas semiestruturadas foram respondidas pela coordenadora e pelos voluntários (no caso destes últimos, seguindo o critério de saturação). 
Conforme Fontanella, Ricas e Turato (2008), o fechamento amostral por saturação é definido com a suspensão de inclusão de novos participantes, quando os dados obtidos passam a apresentar, na avaliação do pesquisador, uma certa repetição, não sendo considerado relevante prosseguir na coleta de dados.

Os roteiros utilizados nas entrevistas semiestruturadas foram baseados em Dohme (2001), Domeneghetti (2001), Corullón e Medeiros Filho (2002). As entrevistas foram realizadas face a face, in loco, e foram gravadas em áudio mediante autorização do entrevistado e assinatura do Termo de Consentimento Livre e Esclarecido (TCLE). Depois de gravadas, as entrevistas foram transcritas para apresentação e análise dos dados, totalizando 281 minutos e 111 páginas transcritas. Os documentos utilizados foram os disponíveis e os cedidos pelos sujeitos da pesquisa. Também foi utilizada a observação in loco com a finalidade de verificar como o voluntariado está organizado no hospital em termos de estrutura física. As anotações relativas à observação foram registradas em um diário de campo.
O método de análise de dados utilizado foi a análise de conteúdo, que, para Bardin (2010) e Minayo (2007), pode ser definida como um conjunto de técnicas de análise de comunicação que visam obter indicadores (quantitativos ou não) que permitam a conclusão de conhecimentos relativos às condições de produção das mensagens analisadas. Bardin (2010) destaca três etapas do processo de análise de conteúdo: (1) pré-análise; (2) exploração e análise do material; e (3) tratamento, inferência e interpretação. A técnica utilizada na análise de conteúdo foi a análise categorial, que, segundo Bardin (2010), visa agrupar e classificar os dados a fim de facilitar sua interpretação. No Quadro 4, apresentam-se as categorias e as subcategorias de análise da pesquisa.

O estudo foi desenvolvido de acordo com as diretrizes e normas contidas na Resolução $n^{0}$ 466/2012 do Conselho Nacional de Saúde. 0 projeto foi aprovado pelo Comitê de Ética em Pesquisa com Seres Humanos (CEPh-FURB) em 26 de fevereiro de 2015 (Parecer no 966.040).

\section{Quadro 3-Perfil dos entrevistados}

\begin{tabular}{|c|c|c|c|c|c|}
\hline Instituição & Entrevistado & $\begin{array}{l}\text { Tempo de trabalho } \\
\text { voluntário }\end{array}$ & Gênero & Atuação & $\begin{array}{l}\text { Horas dedicadas } \\
\text { por semana }\end{array}$ \\
\hline \multirow{7}{*}{$\begin{array}{l}\text { Hospital } \\
\text { Israelita } \\
\text { Albert } \\
\text { Einstein }\end{array}$} & Voluntário A & Dois anos & Feminino & $\begin{array}{l}\text { Sala de convivência Setor } \\
\text { de oncologia }\end{array}$ & Seis horas \\
\hline & Voluntário B & Um ano & Feminino & $\begin{array}{l}\text { Atendimento } \\
\text { Setor de radioterapia }\end{array}$ & $\begin{array}{l}\text { Quatro horas } \\
\text { e meia }\end{array}$ \\
\hline & Voluntário C & Seis anos & Feminino & $\begin{array}{l}\text { Coordenadora do setor de } \\
\text { apoio ao cliente }\end{array}$ & Quatro horas \\
\hline & Voluntario D & Nove anos & Feminino & $\begin{array}{l}\text { Setor banco de sangue } \\
\text { (captação de doadores) e } \\
\text { Paraisópolis }\end{array}$ & Oito horas \\
\hline & Voluntário E & Doze anos & Feminino & Setor de internação & Quatro horas \\
\hline & Voluntário F & Onze anos & Feminino & $\begin{array}{l}\text { Coordenadora do setor de } \\
\text { quimioterapia } \\
\text { (recebe pessoas) }\end{array}$ & Quatro horas \\
\hline & Coordenadora & Quatorze anos & Feminino & Coordenação & Quarenta horas \\
\hline
\end{tabular}


Quadro 4 - Categorias e subcategorias de análise

\begin{tabular}{|c|c|c|c|}
\hline Categorias & Subcategorias & Descrição & Autores \\
\hline \multirow{6}{*}{$\begin{array}{l}\text { Organização } \\
\text { do } \\
\text { voluntariado }\end{array}$} & Características gerais & Tempo, número de voluntários, perfil dos voluntários. & \multirow{6}{*}{$\begin{array}{l}\text { Corullóne } \\
\text { Medeiros } \\
\text { Filho (2002), } \\
\text { Domeneghetti } \\
\text { (2001) }\end{array}$} \\
\hline & Estruturação & Coordenação, presidência, hierarquia. & \\
\hline & Atuação & Abrangência das ações. & \\
\hline & Benefícios & Benefícios financeiros e sociais. & \\
\hline & Constituição jurídica & Formação jurídica. & \\
\hline & Regimento & Orientação formal do voluntariado. & \\
\hline \multirow{3}{*}{$\begin{array}{l}\text { Funções do } \\
\text { coordenador } \\
\text { do } \\
\text { voluntariado }\end{array}$} & $\begin{array}{l}\text { Supervisãoe } \\
\text { monitoramento }\end{array}$ & Controle e acompanhamento das ações realizadas. & \multirow{3}{*}{$\begin{array}{l}\text { Corullón e } \\
\text { Medeiros } \\
\text { Filho (2002) }\end{array}$} \\
\hline & Avaliação & Verificação dos resultados individuais ou do grupo de voluntários. & \\
\hline & Planejamento & Planejamento estratégico ou das ações do voluntariado. & \\
\hline \multirow{7}{*}{$\begin{array}{l}\text { Processos de } \\
\text { gestão do } \\
\text { voluntariado }\end{array}$} & Seleção & Processo de seleção dos voluntários. & \multirow{7}{*}{ Dohme (200I) } \\
\hline & Treinamento & Processo de treinamento para o trabalho voluntário. & \\
\hline & Capacitação & Capacitações e palestras para o voluntariado. & \\
\hline & Comunicação & Relação entre os membros do voluntariado. & \\
\hline & Controle & Indicadores ou monitoramento do trabalho voluntário. & \\
\hline & Reconhecimento & Ações formais e informais de reconhecimento do trabalho voluntário. & \\
\hline & Desligamento & Procedimentos de desligamento do voluntário. & \\
\hline \multirow{8}{*}{$\begin{array}{l}\text { Percepção } \\
\text { dos } \\
\text { voluntários } \\
\text { sobre a } \\
\text { gestão do } \\
\text { voluntariado }\end{array}$} & Seleção & Processo de seleção dos voluntários. & \multirow{8}{*}{$\begin{array}{l}\text { Dohme } \\
\text { (2001), } \\
\text { Corullóne } \\
\text { Medeiros } \\
\text { Filho (2002) }\end{array}$} \\
\hline & Treinamento & Processo de treinamento para o trabalho voluntário. & \\
\hline & Capacitação & Capacitações e palestras para o voluntariado. & \\
\hline & Comunicação & Relação entre os membros do voluntariado. & \\
\hline & Controle & Indicadores ou monitoramento do trabalho voluntário. & \\
\hline & Avaliação & Verificação dos resultados individuais ou do grupo de voluntários. & \\
\hline & Planejamento & Planejamento estratégico ou das ações do voluntariado. & \\
\hline & Reconhecimento & $\begin{array}{l}\text { Ações formais de reconhecimento do trabalho } \\
\text { voluntário. E reconhecimento informal. }\end{array}$ & \\
\hline
\end{tabular}

\section{Apresentação e discussão dos resultados}

A apresentação e discussão dos resultados será apresentada nas seções seguintes, de acordo com as categorias de análise da pesquisa: organização da área de gestão; funções do coordenador; processos de gestão do voluntariado; e percepção dos voluntários sobre a gestão.

\section{Organização da área de gestão}

O início das ações do voluntariado ocorreu juntamente com a idealização do Hospital Albert Einstein, em 1955. 0 voluntariado teve participação relevante para a própria constituição do hospital, já que, na filosofia dos fundadores, a instituição deveria ter uma faceta assistencial. As voluntárias 
contribuíram inicialmente na distribuição de roupas e outros auxílios a pessoas necessitadas. O trabalho das voluntárias, que eram principalmente esposas de médicos, de diretores e de conselheiros da sociedade, combinava atividades de arrecadação de recursos para a construção do hospital com atividades ligadas diretamente à assistência social. Por um breve período, a Comissão de Atividades Femininas e o Departamento de Assistência Social atuaram em conjunto, formando um só departamento, o Comitê Feminino de Assistência Social. Entretanto, as circunstâncias dividiram o departamento. Aos poucos, o voluntariado foi se organizando, implementando regras e ampliando seu campo de atuação.

O voluntariado é composto basicamente por mulheres, com educação superior e faixa etária entre 41 e 60 anos. A coordenadora do voluntariado afirma que $94 \%$ dos voluntários são mulheres e 6\% homens. Quanto à escolaridade, 59\% têm ensino superior, $16 \%$ ensino médio, $4 \%$ ensino fundamental e $21 \%$ pós-graduação. A maioria do voluntariado (53\%) tem de 41 a 60 anos.

O voluntariado está formalmente organizado e constitui o Departamento de Voluntários, ligado à diretoria do Hospital Albert Einstein e ao Instituto de Responsabilidade Social. Assim, o departamento não possui constituição jurídica própria. Nas palavras da coordenadora entrevistada, o Departamento de Voluntários está subordinado ao Instituto de Responsabilidade Social e também à diretoria do Hospital Israelita Albert Einstein. Está tudo dentro dessa célula-mãe que é a Sociedade Beneficente. [...] É essa célula-mãe que define realmente e é um único CNPJ. Conforme Corullón e Medeiros Filho (2002), o voluntariado pode também estar ligado à questão da responsabilidade social na organização.

O Departamento de Voluntários, segundo a coordenadora entrevistada, é constituído por $\mathrm{dez}$ profissionais contratados que dão suporte a 450 voluntários que atuam em 56 setores e em quatro unidades. Quanto ao grupo de 10 profissionais contratados, o achado corrobora Teodósio (2001), que afirma que um grupo mínimo de pessoas remuneradas é necessário para não comprometer a sobrevivência do projeto em longo prazo. 0 suporte dos profissionais contratados contribui para o bom funcionamento das operações do departamento.

O voluntariado atua em quatro unidades: Morumbi, Paraisópolis, M’Boi Mirim e Vila Mariana. Suas ações abrangem obras de humanização, transformação social e geração de conhecimento.

Nós temos como missão a proposta de humanização, transformação social e também geração de conhecimento. São os pilares, digamos, da nossa missão. Então nós contribuímos com o hospital colocando em prática esses três pilares. (Coordenadora)

De acordo com Nogueira-Martins et al. (2010), as atividades desenvolvidas pelo voluntariado do Hospital Albert Einstein contribuem para a humanização e, ainda, conforme Corullón e Medeiros Filho (2002), reforçam a cultura, ampliam o alcance para a sociedade e colaboram com a inserção da instituição em vários segmentos do público de interesse.

A estrutura e organização do voluntariado proporcionam benefícios importantes, como autonomia de suas ações e agilidade em suas decisões.

Nós temos uma situação bem atípica na instituição comparada às demais áreas e departamentos. o Departamento de Voluntários é um órgão de apoio ligado diretamente à presidência da instituição. Agora, se você me disser: "e vocês, profissionais contratados, esses dez profissionais?". Nós estamos ligados ao voluntariado, é claro, a uma diretoria voluntária a qual eu me reporto diariamente. Mas eu tenho uma diretoria contratada também, que éa Diretoria do Instituto de Responsabilidade Social. $\varepsilon$ todos os profissionais do voluntariado têm um duplo reporte, à diretoria voluntária e a este diretor contratado no Instituto de Responsabilidade Social. Agora, é claro, no dia a dia, se você me perguntar, eumereporto à diretoria do voluntariado. Agora, em situações como descrição de metas, avaliação de desempenho e outras atividades institucionais, eu me reporto a esse diretor do Instituto de Responsabilidade Social. Mas - o que é bacana - o voluntariado, por estar ligado diretamente à presidência da instituição, tem uma 
certa autonomia. E isso para as nossas ações é importante. Para nossas decisões mais rápidas, mais ágeis, enfim... Então, isso facilita o nosso trabalho. (Coordenadora)

Conforme Rodrigues (2014), a atividade de gestão do voluntariado é um processo que requer inovações e mudança. $O$ fato do voluntariado do Hospital Albert Einstein ter certa autonomia em função da estrutura que apresenta e com a qual se relaciona favorece a implantação de inovações.

Segundo a coordenadora do voluntariado, a estrutura organizacional do departamento de voluntários funciona da seguinte forma:

Nós temos uma diretoria. Essa diretoria é composta por dez membros, todos voluntários. Nós temos um presidente, três vice-presidentes, três tesoureiros, duas secretárias e uma coordenadora geral. Todos diretores. Então, cabe a essa diretoria a decisão do planejamento estratégico do voluntariado. Subordinados a essa diretoria, nós temos quatro comissões [formadas por] voluntários da Comunicação, da Comissão de Qualidade, da Captação de Recursos e das Atividades Específicas. A gente tem apoio administrativo [fornecido pelos] profissionais contratados, esses dez que eu te falei. [...] Em cada uma das unidades que eu te falei, eu tenho um coordenador da unidade. Então, eu tenho um coordenador do Morumbi e avançadas, eu tenho um coordenador em Paraisópolis, Vila Mariana e M'Boi Mirim. Subordinados a esse coordenador da unidade, eu tenho os setoriais. Então, por exemplo, no Morumbi, eu tenho 14 setores, cada um tem um coordenador voluntário. (Coordenadora)

O voluntariado reporta-se ao estatuto da Sociedade Beneficente do Hospital Albert Einstein e também possui um Manual da Qualidade que define e orienta suas ações.

Nós fazemos parte da instituição, como eu te disse, não somos uma organização independente. Como nós fazemos parte da instituição, quem tem o estatuto não é o voluntariado, e sim a Sociedade Beneficente Israelita Brasileira Albert Einstein, que é a sociedade mantenedora de toda estrutura da instituição. Então, nós nos reportamos a esta sociedade e a este estatuto. O voluntariado, o que nós temos, com o nosso Sistema da Qualidade, é o nosso Manual da Qualidade. Então, ele é o nosso, digamos, norteador. Então, neste Manual da Qualidade, nós temos a nossa linha geral, missão, visão, valores, política da qualidade, objetivos da qualidade, organograma, definição de atribuições de cada membro da diretoria, de cada voluntário, de cada profissional contratado. Nós temos a descrição de todos os macroprocessos do voluntariado neste manual. Então, ele é o nosso grande guia. (Coordenadora)

De acordo com Domeneghetti (2001), o departamento de voluntários também deve possuir um regimento ou estatuto interno que definirá seu modo de atuação, as regras e as formas de comportamento a serem seguidas. Neste sentido, o voluntariado do Hospital Albert Einstein está bem organizado, corroborando também os critérios estabelecidos por Dohme (2001), Corullón e Medeiros Filho (2002) e Rodrigues (2014), que são os sistemas de regras necessários para sua funcionalização.

O Departamento de Voluntários possui uma estrutura física e atende às condições necessárias para realizar seu trabalho. 0 mesmo pôde ser observado nas entrevistas com os voluntários, realizadas in loco. Ainda, conforme observação, os voluntários são identificados por crachás e um avental rosa. De acordo com Domeneghetti (2001) é necessário que o voluntariado possua um local próprio para fixação de avisos, livro de ponto, guarda de pertences e até para tomar um cafezinho. $\mathrm{O}$ ideal, inclusive, é contratar uma secretaria em tempo integral, que esteja a par de tudo e seja responsável pelo arquivo, pelo computador etc. 0 cumprimento de todos estes requisitos foi observado no Departamento de Voluntários do Hospital Albert Einstein. Em relação aos benefícios concedidos aos voluntários, destaca-se o estacionamento e o almoço.

\section{Funções do coordenador}

A coordenação possui uma estrutura composta por um coordenador profissional, coordenadores de unidades e coordenadores de setores, sendo o 
coordenador setorial a principal referência quanto à supervisão e monitoramento do trabalho voluntário.

O coordenador setorial énossa principal referência na prática. Então, assim, os voluntários, eles são treinados pelo coordenador, monitorados pelo coordenador. Se eles têm algum tipo de problema, seja de ordem de relacionamento ou ordem técnica, quem dá o suporte é esse coordenador. E quando ele não consegue, o que ele faz? Ele se reporta ao coordenador da unidade: "me ajude que eu estou com um problema mais sério aqui que eu não consigo resolver". Então o coordenador da unidade entra no circuito. Quando o coordenador de unidade não tem autonomia ou não conseguiu resolver o problema por alguma razão, ele se reporta a quem? À diretoria. (Coordenadora)

Existe por parte da coordenação e da presidência do voluntariado uma avaliação dos resultados alcançados com acompanhamento de metas, monitoramento de indicadores e planejamento estratégico realizado por meio da análise crítica.

A análise crítica é uma proposta do Sistema da Qualidade. Então, é muito rico. O que propõe o sistema? Que duas vezes por ano você reúna toda a sua diretoria para discutir questões estratégicas. Então isto acontece no primeiro semestre e no segundo. No primeiro semestre, o que nós avaliamos? Em primeiro lugar, os indicadores das quatro unidades, indicadores de presença, de produtividade. Então nós repassamos setor por setor. Se os voluntários têm baixo índice de presença em um setor, nós avaliamos quais são os motivos. Acionamos os coordenadores, para que eles entrem no circuito. Isso em cada setor. Então é, digamos assim, uma varredura por todas as unidades, por todos os setores, avaliação mesmo. No final do ano, em novembro, nós retomamos, tem mais uma seção. São cinco ou seis reuniões de análise crítica. Só que no final do ano nós avaliamos o cumprimento das metas durante o ano, avaliamos o andamento dos nossos indicadores, todos os indicadores que nós temos aqui e, além disso, traçamos metas para o ano seguinte. Entãoéemnovembro que a gentevai traçar, éclaro, as metas para o ano de 2016. (Coordenadora)
De acordo com Corullón e Medeiros Filho (2002), supervisão e monitoramento referem-se a dar instruções e facilitar os meios necessários à execução da tarefa para o trabalho voluntário e monitorar a atividade para verificar se está sendo adequadamente realizada e se às necessidades dos voluntários estão sendo satisfeitas. Neste sentido, os processos estão sendo realizados pela coordenação do voluntariado do Hospital Albert Einstein. Também se encontra presente o planejamento estratégico intermediado pelo Instituto de Responsabilidade Social. Conforme Domeneghetti (2001), o planejamento estratégico é um conjunto de regras de tomada de decisão traçadas para atingir os objetivos derivados da missão da instituição.

Ainda em relação ao planejamento, a entrevistada destacou a dinâmica das rotinas específicas estabelecidas no Manual da Qualidade.

Na verdade, assim, de planejamento nós temos as rotinas específicas de cada setor [Manual da Qualidade]. Então, sevocême perguntar: isso muda a cada ano? Não. Na verdade, a rotina específica existe e sofre alterações com o passar do tempo. Claro, nada é estático. Tudo é dinâmico. Então existem coisas que hoje o voluntário faz, por exemplo na UTI, que amanhã talvez ele não faça. Talvez ele assuma outras atribuições. Cada vez que existe uma mudança no setor, nós geramos uma nova versão dessa rotina específica. [...] $\varepsilon$ dessa forma que nós planejamos e monitoramos as atividades do dia a dia. (Coordenadora)

Conforme Corullón e Medeiros Filho (2002), os programas de voluntariado precisam ser planejados e periodicamente replanejados. Uma das funções da avaliação é fornecer dados para o replanejamento, incluindo o que vai mal, mas também as descobertas de novas demandas identificadas. Este processo é realizado com eficiência com o Manual da Qualidade.

As atividades da coordenação são abrangentes devido à diversidade de ações exercidas pelo voluntariado e envolvem ações além das dependências físicas do Hospital. Todos os assuntos relacionados ao voluntariado e sua gestão são discutidos em uma reunião realizada semanalmente. Conforme Dohme (2001), uma equipe de trabalho 
não tem outra forma de expressão além daquela advinda de uma reunião.

\section{Processos de gestão do voluntariado}

Os processos de gestão envolvem o recrutamento, execução e término do trabalho voluntário. O processo de recrutamento envolve ações de captação, seleção e treinamento do voluntariado. No Departamento de Voluntários do Hospital Albert Einstein, a captação inicia-se com a apresentação de uma palestra a todos interessados: todos os meses nós apresentamos uma palestra para candidatos. Para todos os interessados. Então é uma demanda de 30 a 40 pessoas por mês (Coordenadora).

O processo de seleção respeita o desejo de atuação do voluntário dentre as opções oferecidas pelo departamento e passa pela realização de uma dinâmica entre todos os candidatos à vaga ofertada.

A gente respeita essa identificação do voluntário, do candidato a voluntário. Quando ele vem para a palestra, ele conhece as quatro unidades, os 56 setores de atuação, e ele opta no momento do preenchimento da ficha. [...] $\varepsilon$ aí, na sequência, nós fazemos uma dinâmica de grupo por unidade de atuação. (Coordenadora)

O treinamento é realizado em um período de três meses, caracterizado como estágio, e um programa de integração composto por três etapas.

Eles são treinados durante três meses, durante esse período que nós chamamos de estágio. Criase um vínculo muito intenso entre o voluntário e o coordenador. [...] Eu, como coordenadora, serei o seu principal reporte e principal referência. [...] o voluntário novo, ele participa de um programa de integração que é composto por três etapas. Numa primeira etapa, nós explicamos... Nós temos hoje 14 rotinas gerais que norteiam o nosso trabalho, além do Manual da Qualidade. Então, o manual [conta com] 14 rotinas que se aplicam a todos os voluntários, e eu tenho a rotina especifica de cada setor. Numa segunda etapa, ele [o voluntário] tem acesso às demais rotinas gerais e ao Manual da Qualidade. Ali ele conhece toda a nossa documentação. $\varepsilon$, numa terceira etapa, ele participa de uma integração do Einstein, institucional. Porque ele não vai ser voluntário aqui, então é importante que ele conheça as regras da instituição. (Coordenadora)

De acordo com Dohme (2001), o processo de recrutamento envolve seleção composta por entrevista - expondo ao candidato elementos necessários para sua atuação -, avaliação prévia de adequação às necessidades da vaga e processo de integração, em que o candidato conhece a estrutura da instituição e é treinado para a função que irá executar enquanto voluntário. Por fim, há a assinatura do termo de adesão ao trabalho voluntário. No Departamento de Voluntários do Hospital Albert Einstein, todas as etapas do processo de recrutamento foram identificadas e encontram-se formalizadas.

O processo de execução abrange as ações de capacitação, comunicação, controle, avaliação e reconhecimento do trabalho voluntário. A capacitação dos voluntários está relacionada a temas comportamentais e é realizada por consultorias contratadas, que treinam também os próprios funcionários do hospital.

A cada ano nós determinamos os temas mais necessários e adequados. Mas, todo ano, eles [os voluntários] são convidados para diversos treinamentos, não só esse estágio prático, que é o primeiro grande treinamento, como outros que se aplicam a todos os voluntários. [...] Todo ano elas [as voluntárias] fazem reciclagem do nosso programa da qualidade. Nós normalmente contratamos consultorias para treinar voluntários anualmente, em temas normalmente comportamentais. (Coordenadora)

A comunicação entre os voluntários é realizada por meio de diversos canais, não necessariamente presenciais:

Existe um vínculo muito bom entre voluntários e coordenadores. Não necessariamente presencial, mas e-mail, WhatsApp... Eles formam grupos, enfim, eles se comunicam de diversas maneiras. Celular, é claro, hoje você encontra pessoas onde quer que elas 
estejam. Então ele [o voluntário] consegue atuar mesmo que a distância. (Coordenadora)

Ainda em relação à supervisão, monitoramento e controle, a entrevistada relatou a realização dos seguintes procedimentos:

Cada coordenador tem que fazer uma reunião por semestre, com toda equipe e com ata, e entregar aqui na administração para que a gente acompanhe o que está acontecendo. É claro que nós acompanhamos, porque cada unidade tem um profissional que monitora, mas é importante ouvir do voluntário também. Nós acompanhamos essas reuniões, como está o trabalho de vocês, quais são as dificuldades encontradas, quais são os pontos fortes, como vai a relação com o profissional de referência... (Coordenadora)

Já no tocante à avaliação de desempenho, dois tipos de avaliação, individual e de grupo, foram observadas.

Nós temos os dois. $O$ individual fica muito entre coordenador setorial e voluntário. Então, essa avaliação, ela acontece no período de experiência. [...] Depois as avaliações são constantes e informais, entre coordenador e voluntário. Além disso, é uma prática nossa, conversar com os gestores profissionais para que eles nos digam como vai o trabalho voluntário no setor deles. Essa avaliação para nós é muito rica também. [...] Nós temos um roteiro e ele [o gestor] responde, e assim, em linhas gerais, é para ele avaliar se o trabalho voluntário naquele setor está adequado, comoéo relacionamento entre voluntários e profissionais, e se ele recomenda a continuidade do trabalho. Isso nós fazemos uma vez por ano com o gestor. Além disso, nós contratamos anualmente uma empresa que faz pesquisas com os clientes do voluntariado. Eumaúltima forma também de avaliação é via $S A C$ [serviço de atendimento ao cliente]. Sempre que um elogio ou uma crítica é registrado, nós recebemos via sistema e divulgamos para aquela equipe. (Coordenadora)

O reconhecimento do trabalho voluntário acontece de modo formal e informal. o reconhecimento, nós normalmente apresentamos numa reunião geral. Nós temos uma reunião geral por ano, na qual nós convidamos todos os voluntários [...] $\varepsilon$ neste momento nós apresentamos - em linhas gerais, é claro - o resultado, a produtividade de cada um dos setores. $\varepsilon$ claro que parabenizamos. Então, digamos que é o reconhecimento oficial, que acontece por meio da diretoria para todos os voluntários. Além disso, existe o reconhecimento diretamente feito pelo coordenador em relação a sua equipe, e nós orientamos esse coordenador com certa frequência. É importante que você reconheça talentos, que você elogie, que você valorize e tente até buscar, tente aproximar esses talentos de você. Tanto que até nós criamos o cargo de vicecoordenador, justamente para essas pessoas que se destacam e que têm um certo potencial para líder. [...] Então, também é uma forma de reconhecer, de valorizar talentos e tudo mais. (Coordenadora)

Conforme observado no depoimento da entrevistada, os processos de execução do trabalho voluntário apontados por Dohme (2001), que envolvem programas de capacitação, comunicação, controle, monitoramento e reconhecimento do trabalho, puderam ser identificados no departamento.

Quanto ao processo de término ou desligamento do voluntário, as informações são monitoradas e o desligamento é analisado, conforme procedimento previsto no Manual da Qualidade.

Existe um processo também, e uma rotina falando sobre isso. Então, o voluntário, quando ele decide se desligar, nós solicitamos que ele marque uma entrevista com o nosso analista responsável na qual ele vai dizer qual foi o motivo. [...] $\varepsilon$ importante que a gente saiba, para que, caso necessário, a gente implemente alguma ação corretiva. [...] Nós apresentamos isso para nossa diretoria. Então, por exemplo, de dez voluntários que se desligaram, $80 \%$ foi devido a fatores pessoais, trabalho, doença, mudança de cidade ou outros. E, sei lá, $20 \%$ porfatores relacionados ao voluntariado. Eaínós apresentamos o que foi dito, o que foi feito, qual foi o parecer da diretoria em relação a isso. (Coordenadora) 
Para Dohme (2001), o processo de desligamento ou término pode ser gerenciado por meio de contrato com prazo determinado, que, perante avaliação e desejo das partes, pode ser renovado, havendo também a possibilidade de remanejamento do voluntário para outras funções. Novamente, o Departamento de Voluntários do Hospital Albert Einstein corresponde à literatura e inclusive vai além, implementando indicadores de avaliação, monitoramento e análise do processo de desligamento.

\section{Percepção dos voluntários sobre a gestão}

A seguir, apresenta-se a percepção dos voluntários do departamento quanto à gestão do voluntariado. Esta percepção se refere aos processos de seleção, treinamento, conhecimento das normas, capacitação, atuação, avaliação, planejamento e reconhecimento. O Quadro 5 apresenta algumas das respostas coletadas nas entrevistas com os voluntários, de acordo com as categorias da pesquisa.

\section{Quadro 5 - Percepção dos voluntários sobre a gestão do voluntariado}

\begin{tabular}{|c|c|}
\hline Subcategorias & Hospital Albert Einstein \\
\hline Seleção & 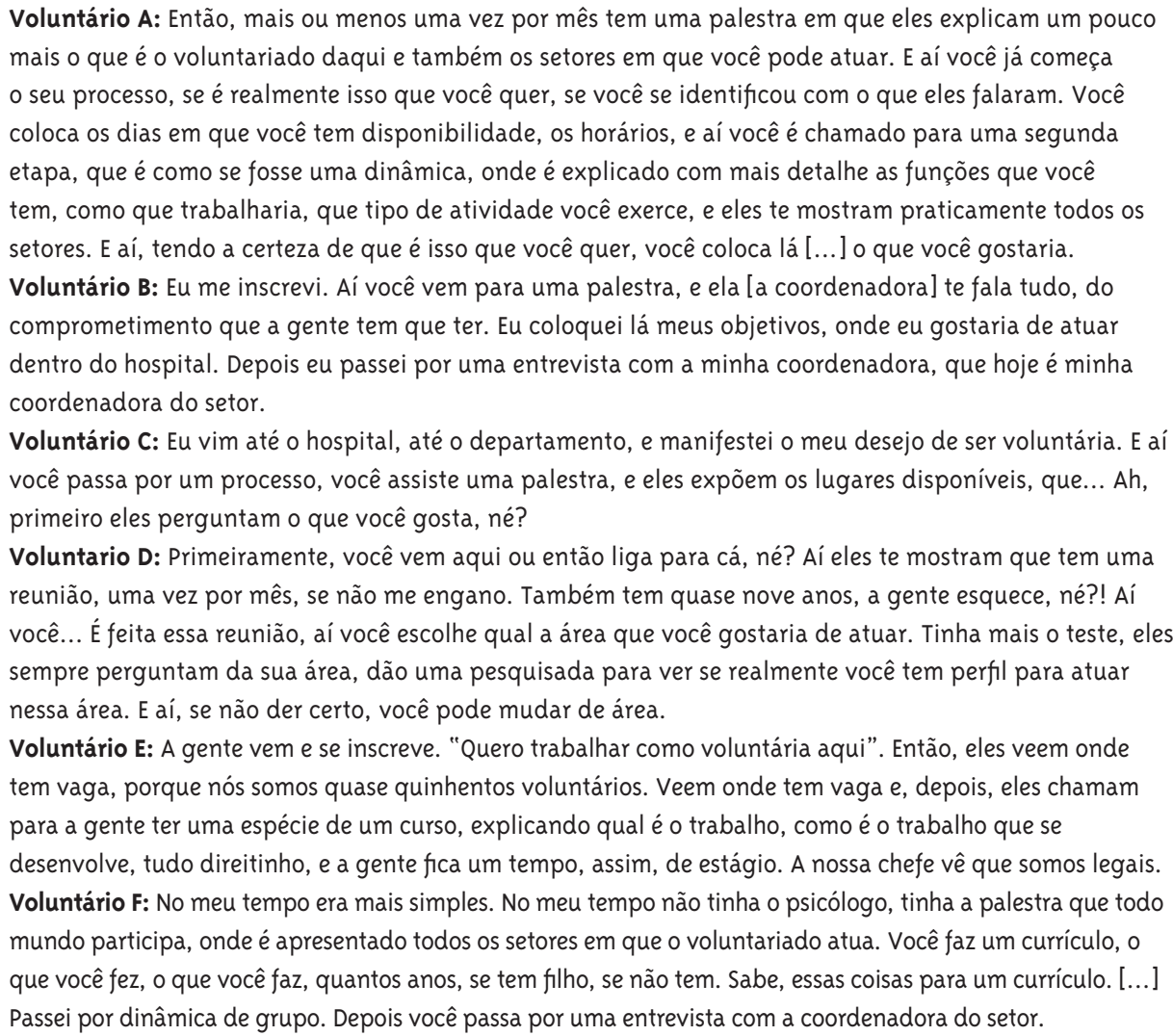 \\
\hline Treinamento & $\begin{array}{l}\text { Voluntário A: São três meses. A gente tem que fazer os treinamentos, a gente passa por... Todo ano tem } \\
\text { treinamento. Está começando uma nova etapa de treinamento agora, a gente recebe várias informações } \\
\text { da Instituição Einstein, várias informações do voluntariado. A gente tem que passar por esse treinamento, } \\
\text { tanto da parte do Einstein como do hospital, a parte de emergência, a parte de como é uma instituição } \\
\text { de hospital. Muitas pessoas nunca trabalharam dentro de um hospital e nem sabem como é, então eles } \\
\text { explicam bem essa parte. E a gente recebe como se fosse uma apostila falando como que deve ser, sua } \\
\text { conduta, como são os valores, missões da empresa, tanto da parte de voluntariado como do Einstein, } \\
\text { uniforme, como você deve se portar, quais são as características de um voluntário do Einstein aqui. }\end{array}$ \\
\hline
\end{tabular}




\section{Quadro 5 - Continuação}

\begin{tabular}{|c|c|}
\hline Subcategorias & Hospital Albert Einstein \\
\hline Treinamento & $\begin{array}{l}\text { Voluntário B: Passei por treinamentos, junto com outras voluntárias do meu setor, passei por integração } \\
\text { com o RH, e depois de } 60 \text { dias fazendo todos esses treinamentos, fazendo essa integração com o hospital, } \\
\text { aí eu fiquei sozinha. } \\
\text { Voluntário C: Você tem um treinamento, você fica em um período até de... você fica uns dois meses, aí } \\
\text { nesse periodo eles vão te analisando, se você dá ou não. Você tem esse período, eles vão te analisando, se } \\
\text { você conseguir tudo bem. Nesse período você fica com alguém te ajudando, um coordenador, um outro } \\
\text { voluntário. E depois você tem que ficar sozinho. } \\
\text { Voluntario D: você fica três meses em teste, para ver se é realmente aquilo que você quer fazer. Se você, } \\
\text { vamos supor, não gostar, você tem a oportunidade de mudar. Mas aí eu fui para lá e adorei Paraisópolis. } \\
\text { Nesses três meses você sempre acaba fazendo com a coordenadora. Não é que você é largada sozinha. } \\
\text { Não. Você tem três meses junto com a coordenadora para você realmente aprender a sua função. Para } \\
\text { poder lidar com cada problema que possa aparecer no meio do caminho. } \\
\text { Voluntário E: Eles chamam para a gente ter uma espécie de um curso, explicando qual é o trabalho, } \\
\text { como é o trabalho que se desenvolve, tudo direitinho, e a gente fica um tempo, assim, de estágio. A } \\
\text { nossa chefe vê que somos legais. } \\
\text { Voluntário F: Por exemplo, eu sou a coordenadora da quimio hoje. Eu, quando escolho alguém, eu fico } \\
\text { três meses do lado das pessoas que é para ensinar tudo e, olha, eu não escondo nada. [...] Então, eu faço } \\
\text { questão de treiná-lo. }\end{array}$ \\
\hline Capacitação & $\begin{array}{l}\text { Voluntário A: Sim, a gente recebe bastante convite, tanto de eventos mesmo, que acontecem } \\
\text { internamente no Einstein, apresentações, entretenimento, como alguns, assim, de ajudar o pessoal, } \\
\text { autoconhecimento, como de ajuda... Enfim, eu já recebi vários tipos de convites. Então, eles promovem } \\
\text { bastante atividades para gente. Como voluntário, então, se a gente quiser, a gente consegue ter várias } \\
\text { outras atividades, não só a do trabalho do voluntariado. Então, a gente consegue assistir a um concerto, } \\
\text { que já aconteceu, vêm alguns trabalhos de Paraisópolis, que é uma unidade onde o Einstein trabalha } \\
\text { também com voluntariados, ou você pode receber palestras de autoconhecimento, de ajuda. Eles ajudam } \\
\text { bastante com relação a isso. } \\
\text { Voluntário B: Sim. } \\
\text { Voluntário C: Você sempre faz uma reciclagem. } \\
\text { Voluntario D: Nós sempre temos esses cursos também, para ir atualizando, sabe? Então... Necessários, } \\
\text { então hoje eu vou ficar até as quatro, sabe? } \\
\text { Voluntário E: Ah, sim. Sim. De seis em seis meses. } \\
\text { Voluntário F: Nós fizemos o curso para identificação do paciente. Porque não é qualquer um. Você tem } \\
\text { que ter o curso e saber como você vai identificar o paciente. Como colocar a etiqueta, uma para que ele } \\
\text { veja, a outra para o médico ou que quem vai atendê-lo veja. Todas essas coisas. Nós temos curso para } \\
\text { isso. É uma coisa profissional, todos recebem, não só aqui, me dão, quantos cursos, um milhão de cursos } \\
\text { que eu fiz aqui. }\end{array}$ \\
\hline Controle & $\begin{array}{l}\text { Voluntário A: Sim, todos os dias a gente preenche um relatório bem simplificado, mas que com certeza } \\
\text { dá muitos dados para o pessoal do voluntariado, de quantas pessoas a gente atendeu e também a } \\
\text { quantidade de pessoas que tem internadas naquele local que você está. E isso aí a gente tem que fazer } \\
\text { todos os dias, para eles terem uma noção de como está indo. } \\
\text { Voluntário B: Nós temos reuniões a cada semestre, do meu setor e do voluntário tem encontro uma vez } \\
\text { por ano, aqui mesmo no hospital, todas as voluntárias do hospital. Então eles colocam qual foi o objetivo } \\
\text { alcançado e qual é o objetivo para o próximo ano, quem elas... o que pretende alcançar. } \\
\text { Voluntário C: Você sempre é avaliada, eu acho isso importante. [...] De repente você acha que está } \\
\text { ajudando, ajuda de uma determinada forma, e não está, na visão, assim, do hospital como um todo. } \\
\text { Você sempre é avaliado e você faz uma avaliação também do teu pessoal, que de repente está indo } \\
\text { bem, mas de repente tem um que escorrega, você tem que ficar sempre atenta para nunca sair nada da } \\
\text { engrenagem ali, entendeu? }\end{array}$ \\
\hline
\end{tabular}

continua... 


\section{Quadro 5 - Continuação}

\begin{tabular}{|c|c|}
\hline Subcategorias & Hospital Albert Einstein \\
\hline Controle & $\begin{array}{l}\text { Voluntario D: Nós temos uma ficha que nós temos que preencher. Todos os dias que nós fazemos o nosso } \\
\text { plantão, o número de atendimentos que nós fazemos, tanto na parte de telemarketing como na parte de } \\
\text { leitos e UTI. } \\
\text { Voluntário E: Sim. E, a cada seis meses, nós temos uma reavaliação. Agora vamos ter, assim, para } \\
\text { explicar como está a situação atualmente, o que mudou, o que não mudou. o que não deixa de ser uma } \\
\text { forma de controle. Então, a cada seis meses, nós somos chamados para... por exemplo, eles mandam para } \\
\text { nós, pela internet, várias datas. Então, a gente escolhe qual é a data e o horário que nós podemos ir, nos } \\
\text { inscrevemos e recebemos. } \\
\text { Voluntário F: Porque são três meses [no treinamento], um mês e meio você avalia e eles avaliam se } \\
\text { gostam mesmo para ninguém perder tempo. [...] Aqui com o voluntariado, que é também dirigido pelo } \\
\text { ISO gooI. Eu mesma acho que fui diversas vezes auditada. [...] Tem sim. Tem o acompanhamento inicial. } \\
\text { Mas depois é tarefa. }\end{array}$ \\
\hline Planejamento & $\begin{array}{l}\text { Voluntário A: A gente tem reunião com a nossa coordenadora a cada semestre, para realmente discutir, } \\
\text { conversar, entender coisas novas que estão vindo, então a nossa coordenadora conversa muito com a } \\
\text { gente, e é bom também, porque é uma hora que a gente reúne todas do mesmo setor. } \\
\text { Voluntário B: Com relação a ela [coordenadora do setor], uma coisa que eu puder falar, eu sempre me } \\
\text { dirijo a ela. } \\
\text { Voluntário C: Mas você tem sim, você não pode fazer, você vai com o tempo anotando sugestões. Por isso que } \\
\text { são feitas essas reuniões setoriais, ou essas reuniões extras que eu também te falo que a gente faz. De repente, } \\
\text { a gente fala em conjunto: "vamos dar uma sugestão" [...]. Por exemplo, às vezes mudanças que ocorrem, que } \\
\text { eles acham que sejam necessárias, eles te comunicam e você tem que fazer, mas eles estão abertos a sugestões. } \\
\text { Voluntario D: Duas vezes por ano nós temos reuniões com os nossos coordenadores. Então, nessas reuniões, } \\
\text { aí sim você pode tentar mostrar que existem aspectos que estão falhando, que podem ser melhorados. } \\
\text { Então, a principio você passa, que nós temos uma hierarquia né, você passa para a sua coordenadora e, aí } \\
\text { sim, depois, a coordenadora tem a reunião dos coordenadores, então aí eles discutem para tentar melhorar } \\
\text { aquilo que pode ser melhorado. Porque existe essa hierarquia, apesar de que eles dão liberdade, então se } \\
\text { tiver alguma coisa a gente até conversa, mas a principio tem que manter a hierarquia. } \\
\text { Voluntário E: Só nas reuniões das voluntárias. Não direto em diretoria. Essas coisas, não. Só durante as } \\
\text { reuniões das voluntárias com a minha chefe. } \\
\text { Voluntário F: Todas as sugestões são apresentadas à coordenação do setor. o pessoal voluntário não } \\
\text { se dirige diretamente à diretoria, pois existe uma hierarquia a seguir. Eles fazem o planejamento, os } \\
\text { voluntários apenas dão sugestões de melhoria que posteriormente são levadas à diretoria e analisadas. }\end{array}$ \\
\hline Reconhecimento & $\begin{array}{l}\text { Voluntário A: Alguns médicos, algumas pessoas que dão esse feedback para a gente, falando que nosso } \\
\text { trabalho é muito importante, enfim, ou alguma coisa específica de algum paciente que deu certo de a } \\
\text { gente conseguir ajudar de alguma forma. } \\
\text { Voluntário B: Tem no paciente, que faz o reconhecimento por escrito. Eles sempre fazem por escrito, } \\
\text { isso vai direto para a diretoria. Tem paciente elogiando o atendimento de todas as voluntárias do nosso } \\
\text { departamento. } \\
\text { Voluntário C: Olha, o que existe é o retorno que eu te falei, da pessoa. Reconhecimento, por exemplo, } \\
\text { aqui da direção, eu não sei se pode ser um reconhecimento, mas eu, por exemplo, era voluntária e eu } \\
\text { fui... me recomendaram como coordenadora. Então, para mim foi reconhecimento, porque eu acho que } \\
\text { eles depositaram confiança no meu trabalho. Acreditaram no meu trabalho. Então é importante. [...] Eu } \\
\text { converso com alguns médicos, você acaba conhecendo e tal, e eles mesmo falam como é importante o } \\
\text { trabalho, como é importante ter uma voluntária, um voluntário para ajudar, para humanizar o hospital. } \\
\text { Voluntario D: Sim, com certeza. Sempre agradecendo. Muitos até falam que pensam em um dia ser } \\
\text { voluntário, então a gente até indica se quiser, mas a maioria, sempre muito agradecido pelo trabalho, } \\
\text { porque às vezes são pessoas não recebem nem visita. Então só o simples fato de você entrar e conversar } \\
\text { um pouquinho com aquela pessoa, sabe, ela já se sente realizada naquele dia. }\end{array}$ \\
\hline
\end{tabular}




\section{Quadro 5 - Continuação}

\begin{tabular}{|l|l|}
\hline \multirow{1}{*}{ Subcategorias } & Hospital Albert Einstein \\
\hline \multirow{3}{*}{ Reconhecimento } & $\begin{array}{l}\text { Voluntário E: Bom, nós temos um almoço maravilhoso no fim do ano que o hospital convida a gente e } \\
\text { tudo. É um salão muito chique e muito bonito que a gente vai no fim do ano. Não tem essa coisa de dar } \\
\text { medalhinha. Por exemplo, se derem o meu nome é porque sabem o meu valor aqui. Depois, no meio do } \\
\text { ano, quando tem essa reavaliação, vamos dizer, tem aqui o Viena, que é um restaurante muito conhecido } \\
\text { aqui, eles convidam as voluntárias para um lanche ou uma coisa assim. } \\
\text { Voluntário F: Lá no meu outro departamento, quando eles estavam em reforma, fazendo a planta, eles } \\
\text { me chamaram para participar, para ver como é que ia ser. Então, você não é voluntário, você é parte } \\
\text { daquilo mesmo. }\end{array}$ \\
\hline
\end{tabular}

Conforme Dohme (2001), o programa de voluntariado não ocorre de forma isolada, mas faz parte de um corpo maior. Por isso, há também a necessidade de integração com as regras e com o funcionamento do hospital. No mais, de acordo com Domeneghetti (2001), é direito do voluntário integrarse à instituição e contar com instrumentos que auxiliem seu trabalho, como no caso de livros sobre as regras do voluntariado e do hospital. Conforme exposto nas entrevistas do Quadro 5, os voluntários apresentaram relatos muito coerentes entre si quanto à percepção em relação ao trabalho realizado e sobre a gestão do voluntariado da instituição. Além disso, os resultados encontrados foram convergentes com o exposto por Domeneghetti (2001), Dohme (2001) e Corullón e Medeiros Filho (2002) no que tange aos processos de gestão de voluntariado.

A profissionalização do voluntariado do Hospital Albert Einstein foi considerada pelos voluntários entrevistados como positiva e relevante. Conforme observado nas entrevistas, os voluntários demonstraram comprometimento com o trabalho, ciência das regras do departamento, da hierarquia, das avaliações de seu trabalho e dos processos de controle. Não foram constatadas contradições entre os sujeitos da pesquisa, ou seja, entre coordenadora e voluntários entrevistados. Assim, os sujeitos da pesquisa concordaram entre si, contribuindo para a validade e confiabilidade desta.

\section{Considerações finais}

Os resultados apontam que o voluntariado não pode agir de maneira independente dentro do hospital, embora a autonomia seja necessária para poder implementar ações que tragam resultados. O voluntariado deve atuar de maneira a se adequar às regras do hospital, não podendo ser um grupo fechado atuando sob suas próprias regras, com o risco de encontrar resistência e problemas que podem colocar em risco inclusive sua existência na instituição. Todas as suas ações precisam estar de acordo com os princípios e objetivos do hospital.

Acredita-se que a gestão do voluntariado vai muito além da gestão de pessoas, gestão participativa, resultados ou aspectos assistencialistas, envolvendo aspectos mais amplos e processos tradicionais de administração juntamente com as características do voluntariado. De qualquer modo, a presença do voluntariado nas instituições contribui de maneira estratégica, em sintonia com a missão, visão e valores do hospital. De fato, é surpreendente ver o quão relevante e grandioso pode ser o trabalho voluntário no hospital.

Conclui-se que, diante das possibilidades que a atuação do voluntariado proporciona ao hospital, cabe à instituição não somente reconhecer seu trabalho e dedicação, mas proporcionar meios para que esse trabalho seja eficientemente realizado. Por outro lado, cabe à gestão do voluntariado buscar o aperfeiçoamento, inovações e instrumentos que permitam prestar contas e divulgar os resultados e ainda administrar todas as dinâmicas que envolvem o voluntariado. Neste ponto o processo de profissionalização da gestão do voluntariado torna-se fundamental.

Diante dos resultados encontrados, recomenda-se ao Hospital Albert Einstein, se possível, implementar ações do voluntariado que possam proporcionar conforto e bem-estar, direcionadas aos funcionários 
da instituição. Esse stakeholder interno, devido ao ambiente de trabalho, muitas vezes necessita de tanta atenção quanto à dada aos clientes do hospital.

Como sugestão para futuras pesquisas sobre o tema, recomenda-se incluir na avaliação da percepção do voluntariado outros atores, como os gestores do hospital, os funcionários e os clientes. Essa avaliação possibilita um diagnóstico mais completo da relevância do voluntariado nas organizações, e em específico nos hospitais, trazendo também informações que poderiam auxiliar a gestão do voluntariado. Novas pesquisas podem utilizar as categorias apresentadas neste estudo para analisar e avaliar a gestão do voluntariado em outras organizações, de modo a identificar padrões e comportamentos que visam contribuir para o avanço neste tema. Além disso, futuros estudos podem avaliar a influência da gestão do trabalho voluntário para a estratégia de hospitais e outras organizações que possuem voluntariado. Por fim, destacam-se as limitações do presente estudo, entre elas, a interpretação do pesquisador e dos sujeitos da pesquisa sobre a realidade estudada.

\section{Referências}

BARDIN, L. Análise de conteúdo. Lisboa: Edições 70, 2010.

CORULLÓN, M. B. G.; MEDEIROS FILHO, B. Voluntariado na empresa: gestão eficiente da participação cidadã. São Paulo: Peirópolis, 2002.

DOHME, V. Voluntariado: equipes produtivas: como liderar ou fazer parte de uma delas. São Paulo: Editora Mackenzie, 2001.

DOMENEGHETTI, A. M. Voluntariado: gestão do trabalho voluntário em organizações sem fins lucrativos. São Paulo: Esfera, 2001.

ENGEL, W. A década dos voluntários: o papel do voluntariado empresarial. In: VALE. Olhares sobre o voluntariado corporativo. Rio de Janeiro, 2012. p. 16-24.

FONTANELLA, B. J. B.; RICAS, J.; TURATO, E. R. Amostragem por saturação em pesquisas qualitativas em saúde: contribuições teóricas. Cadernos de Saúde Pública, Rio de Janeiro, v. 24, n. 1, p. 17-27, 2008.
FOUCAULT, M. O nascimento do hospital. In: . Microfísica do poder. Rio de Janeiro: Graal, 1984. p. 99-111.

HWANG, H.; POWELL, W. W. The rationalization of charity: the influences of professionalism in the nonprofit sector. Administrative Science Quarterly, New York, v. 54, n. 2, p. 268-298, 2009.

MEYER JUNIOR, V.; PASCUCCI, L.; MURPHY, P. Volunteers in Brazilian hospitals: good citizens or strategic agents? Voluntas, New York, v. 24, n. 2, p. 293-310, 2012.

MINAYO, M. C. S. O desafio do conhecimento: pesquisa qualitativa em saúde. São Paulo: Hucitec, 2007.

NOGUEIRA-MARTINS, M. C. F.; BERSUSA, A. A. S.; SIQUEIRA, S. R. Humanização e voluntariado: estudo qualitativo em hospitais públicos. Revista de Saúde Pública, São Paulo, v. 44, n. 5, p. 942-949, 2010.

OKABAYASHI, R. Y.; COSTA, S. F. O serviço voluntário em hospitais do terceiro setor em Londrina: da sua configuração à construção de novos referenciais de gestão. Serviço Social em Revista, Londrina, v. 10, n. 2, p. 14-25, 2008.

PORCIUNCULA, J. Organização e gestão do trabalho voluntário: um estudo comparativo em instituições hospitalares Brasil-EUA. 2009. Dissertação (Mestrado em Desenvolvimento) Universidade Regional do Noroeste do Estado do Rio Grande do Sul, Ijuí, 2009.

RICHARDSON, R. J. Pesquisa Social: métodos e técnicas. São Paulo: Atlas, 2012.

RODRIGUES, K. M. O trabalho voluntário de sua gestão: um estudo de caso em hospital comunitário. 2014. Dissertação (Mestrado em Administração) - Escola de Negócios, Pontifícia Universidade do Paraná, Curitiba, 2014.

RODRIGUES, K. M.; MEYER JUNIOR, V.; CRUZ, J. A. W. Trabalho voluntário e seu gerenciamento: desafios para um hospital comunitário. Revista de Administração Hospitalar e Inovação em Saúde, Belo Horizonte, v. 11, n. 4, p. 306-323, 2014.

SILVA, K. V. S.; MORETTO NETO, L. O processo de gestão do voluntariado: um estudo de caso 
na Associação Amigos do Hospital. Revista de Administração da UEG, Anápolis, v. 2, n. 2, p. 3-22, 2012.

SOBOLH, T.; WIDMAN, S. Voluntariado, a possibilidade da esperança: cenário do trabalho voluntário no Brasil. São Paulo: Voluntários Einstein, 2011.
TEODóSIO, A. S. S. Organização do trabalho voluntário: estratégias para a gestão social no Brasil. In: ENCONTRO NACIONAL DE ENGENHARIA DE PRODUÇÃO, 21., 2001, Salvador. Anais... Rio de Janeiro: Abepro, 2001.

YIN, R. K. Estudo de caso: planejamento e métodos. Porto Alegre: Bookman, 2005.

\section{Contribuição dos autores}

Beckhauser foi responsável pela coleta e análise dos dados. Maria foi responsável pela concepção do estudo. As duas autoras contribuíram para a redação do artigo.

Recebido: 18/04/2017

Reapresentado: 20/10/2017

Aprovado: $31 / 10 / 2017$ 